\title{
Correction to: Gambling and Social Cognition: a Systematic Review
}

\section{Elodie Hurel $^{1,2} \cdot$ Gaëlle Challet-Bouju $^{1,2} \cdot$ Nicolas Bukowski $^{1} \cdot$ Emeline Eyzop $^{1} \cdot$ Marie Grall-Bronnec $^{1,2}$}

Published online: 5 December 2019

(C) Springer Nature Switzerland AG 2019

\section{Correction to: Current Addiction Reports. https://doi.org/10.1007//40429-019-00280-0}

The original article unfortunately contained a mistake. Some references mentioned in Table 1 have been misplaced and not included in the final bibliography.

The original version has been corrected.

Publisher's Note Springer Nature remains neutral with regard to jurisdictional claims in published maps and institutional affiliations.

The online version of the original article can be found at https://doi.org/ 10.1007/s40429-019-00280-0

Marie Grall-Bronnec

marie.bronnec@chu-nantes.fr

1 Addictology and Psychiatry Department, CHU Nantes, 85, rue Saint Jacques, 44093 Nantes cedex 1, France

2 UMR INSERM 1246 SPHERE, University of Tours, Université of Nantes, Nantes, France 